\title{
La Ruta Pacífica de las Mujeres: repertorios simbólicos en la búsqueda de paz y reconciliación en Colombia*
}

Peaceful Route of Women: Symbolic Repertoires in the Pursuit of Peace and Reconciliation in Colombia

A rota pacifica das mulheres: repertórios simbólicos na procura de paz e reconciliação na Colômbia

\section{Elvira Sánchez-Blake** (iD) orcid.org/0000-0001-8502-1924}

\author{
Artículo de investigación \\ Revista Colombiana de Educación, N.71. Segundo semestre de 2016, Bogotá, Colombia. \\ Para citar: Sánchez-Blake, E. (2016). La ruta pacífica de las mujeres: repertorios sim- \\ bólicos en la búsqueda de paz y reconciliación en Colombia. Revista Colombiana de \\ Educación, (71), 301-319.
}

* Este artículo es el resultado de una beca de investigación de la Comisión Fullbright durante el primer semestre del 2015 y contó con el apoyo del Centro de Estudios de Género de la Facultad de Humanidades de la Universidad del Valle y de la Ruta Pacífica de las Mujeres, seccional Cali, Valle del Cauca. Especial agradecimiento a lliana Colona y a María Teresa Arizabaleta

** Ph.D en Literatura Hispanoamericana con especialización en estudios de género y estudios latinoamericanos. Department of Romance Studies, Cornell University, Ithaca, NY. Profesora asociada, literatura hispanoamericana. Department of Romance and Classical Studies. Michigan State University. Correo electrónico: sblake@amsu.edu 


\section{Resumen}

En este trabajo se indaga sobre las formas estéticas y expresivas que los grupos de mujeres han apropiado para buscar un camino hacia la paz y hacia la reconciliación en Colombia. Se trata de los repertorios simbólicos de la memoria, los cuales representan una nueva expresión testimonial adaptada a las nuevas demandas tanto políticas como históricas del continente. En este proceso las organizaciones de mujeres se han constituido en un eje para la búsqueda de la convivencia pacífica tras un conflicto de larga duración.

Las organizaciones de mujeres han desarrollado un amplio espectro de iniciativas de memoria representadas en repertorios simbólicos a través de prácticas artísticas, activismo y educación. En muchos casos, las mujeres que han experimentado las pérdidas y el dolor, como víctimas del conflicto, al unirse en iniciativas de resistencia han adquirido un poder y un liderazgo en sus comunidades que les ha permitido surgir y convertirse en agentes culturales de cambio, así como en promotoras y formadoras de las nuevas generaciones y en muchos casos, en las representantes de sus regiones ante foros políticos.

Este ensayo se enfoca específicamente en el trabajo de la Ruta Pacífica de las Mujeres y en las iniciativas que están generando una transformación a nivel de sociedad. Se analizan a continuación varios tipos de repertorios simbólicos testimoniales que desarrolla actualmente la Ruta Pacífica como formas de canalizar la memoria, reconstruir el tejido social y transmitir una pedagogía de paz con perspectiva de género a lo largo del país. Se propone que estas iniciativas están generando un cambio a nivel de sociedad en la concientización sobre los derechos y las capacidades de las mujeres, en todos los sectores tanto públicos como privados, y creando el espacio necesario para abordar la transición hacia una cultura de paz en Colombia.

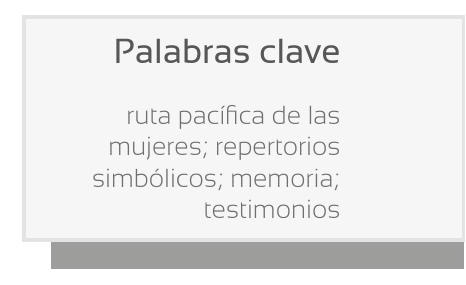

\section{Keywords}

women's peaceful route; symbolic repertoires; memory; testimonials

\begin{abstract}
This paper deals with the aesthetic and expressive forms that women's groups have grasped in the pursuit of peace and reconciliation in Colombia. These forms are the symbolic repertoires of memory, which represent a new testimonial expression, adjusted to the continent's new political and historical demands. Throughout this process, women's organizations have played a central role in the pursuit of peaceful coexistence after a long-lasting conflict.

Women's organizations have developed a broad continuum of memory initiatives, represented in symbolic repertoires through art undertakings, activism and education. Quite frequently, when women that have experienced loss and pain as victims of conflict join together in resistance initiatives, they gain power and leadership within their own communities. This has allowed them to arise and become cultural agents of change, as well as promoters and trainers of new generations. Sometimes, they have even acted as speakers of their regions in political fora.

This paper focuses in the work of Women's Peaceful Route and their initiatives triggering social changes. Some testimonial symbolic repertoires developed by the Peaceful Route are analyzed. They are ways of channeling memory, rebuilding the social fabric and conveying a pedagogy of peace from a gender perspective throughout the country. It is suggested that these initiatives are encouraging social changes in terms of women's rights and capabilities awareness in both public and private sectors, and creating the space needed to address the transition towards a culture of peace in Colombia.
\end{abstract}

\section{Resumo}

Neste trabalho se indaga sobre as formas estéticas e expressivas que os grupos de mulheres têm apropriado para procurar um caminho para a paz e para a reconciliação na Colômbia. Trata-se dos repertórios simbólicos da memória, os quais representam uma nova expressão testemunhal, adaptada ás novas exigências tanto políticas como históricas do continente. Neste processo as organizações de mulheres se têm constituído num eixo para a procura da convivência pacifica depois dum conflito prolongado.

As organizações das mulheres têm desarrolhado um amplo espectro de iniciativas de memória representadas em repertórios simbólicos através de práticas artísticas, ativismo e educação. Em muitos casos, as mulheres que têm experimentado as perdidas e o dor como vitimas do conflito, ao ligar- se em iniciativas de resistência têm adquirido um poder e uma liderança nas suas comunidades o que thes tem permitido surgir e converter- se em agentes culturais da mudança, assim como em promotoras e formadoras das novas gerações e em muitos casos, nas representantes das suas regiões em fóruns políticos.

Este ensaio centra-se especificamente no trabalho da Rota Pacifica das Mulheres e nas inciativas que estão gerando uma transformação ao nível social. Analisam-se também diferentes tipos de repertórios simbólicos testemunha-Ihes que desarrolha atualmente a Rota Pacifica como formas de canalizar a memória, reconstruir o tecido social e transmitir uma pedagogia de paz com perspectiva de gênero ao longo do país. Propõe- se que estas inciativas estão gerando uma mudança ao nível de sociedade na conscientização sobre os direitos e as capanecessário para abordar a transição á uma cultura de paz na Colômbia. 
Cuando logramos hacer incidencia hay una transformación. Somos como las mariposas que se transforman en positivo, como colectividad.

Elizabeth Ortega Ruta Pacífica, Palmira

\section{Organizaciones de mujeres por la paz}

E s imposible enumerar las organizaciones de mujeres que han surgido en la última década en Colombia pues su número se multiplica vertiginosamente. Los movimientos se iniciaron desde la década de los setenta con el nacimiento de La Organización Femenina Popular (OFP). Esta organización surgió como una estrategia de resistencia en procesos de recuperación de tierras en Santander y se fortaleció en la década de los noventa, cuando el objetivo de la organización se dirigió hacia una política de paz (Mujeres en Zona de Conflicto y Corporación Sisma Mujer, 2010). En 1995 se inició una campaña que pretendió incitar a las mujeres a escribir cartas en contra de la guerra, en las que narraran sus experiencias. Se difundió un mensaje que pretendía llegar a la población con el lema "Las mujeres no parimos hijos para la guerra". A partir de esta iniciativa se creó la Red Regional de Mujeres, con presencia en el Magdalena Medio. El objetivo de esta organización era establecer alianzas con otros movimientos de mujeres, denunciar los abusos de los actores armados y establecer diálogos con los estamentos públicos y privados para demandar acciones en contra de los efectos de la guerra. Por último, crearon símbolos que plasmaron en afiches para interpelar la lógica de la guerra (Mujeres en Zona de Conflicto y Corporación Sisma Mujer, 2010).

Paralelo a estos movimientos surgen otras organizaciones, como la Asociación de Mujeres Campesinas e Indígenas de Colombia (Amucic), la cual se originó con el objetivo de reivindicar los derechos de las mujeres campesinas en zonas rurales. Cuando empezaron las amenazas y hostigamientos se unieron a la iniciativa de la Mesa de Mujer y Conflicto Armado y a la Iniciativa de Mujeres por la Paz, que surgieron a finales de los noventa y se consolidaron como una de las organizaciones líderes en materia de paz. Paralelamente, se fundó la Red Nacional de Mujeres, una organización que nació como resultado de la reforma de la Constitución de 1991, y que logró la incorporación del derecho a la igualdad entre hombres y mujeres en la nueva carta política. En 1996 nació la Ruta Pacífica de las Mujeres como reacción a una violación masiva ocurrida en el municipio de Urabá. Las mujeres se unieron en una marcha que reunió a miles de víctimas de diversas localidades. La Ruta Pacífica se constituyó así en uno de los movimientos con mayor visibilidad y accionar permanente. El colectivo se define como, 
... un movimiento pacifista, no armamentista, constructor de una ética de la No violencia, y del reconocimiento de los derechos fundamentales de las mujeres. Sus principios fundamentales son la justicia, la paz, la equidad, la autonomía y el reconocimiento de la otredad (www.rutapacifica.org.co).

A partir del año 2000 su accionar se extendió, con más de 300 organizaciones regionales y locales en todo el país. A lo largo de veinte años de trabajo, la Ruta Pacífica ha logrado consolidar una agenda de iniciativas que incluyen las movilizaciones, los plantones, la militancia, escuelas de formación y concientización y especialmente, una variedad de repertorios simbólicos que operan como bastiones de su quehacer político y social.

\section{Repertorios simbólicos del testimonio}

Diana Taylor distingue entre repertorios y archivos como fuentes de conocimiento. Los repertorios son las prácticas y experiencias que parten del cuerpo y la cotidianidad (la praxis) y los archivos son las fuentes documentales, tales como libros y formas perdurables del saber (episteme) (Taylor, 2003, pp. 16-17). Los repertorios se definen como las expresiones creativas que incluyen la oralidad, el movimiento, la danza y el canto, el teatro, la puesta en escena, actos usualmente considerados efímeros. Etimológicamente, repertorio significa "esoro' o 'inventario', lo cual permite agencia por parte del individuo en los actos de descubrir y producir significados. El repertorio requiere presencia, es decir, la participación activa de los sujetos en la producción y reproducción de conocimiento, estar allí, ser parte activa del mismo. El repertorio transmite y mantiene coreografías de significado, las cuales mantienen el sentido aun a través de los cambios que suceden en el tiempo (Taylor, 2003, p. 20). Estos repertorios se manifiestan por medio de lo que la autora llama performances, lo que permite a la gente participar en la producción y reproducción de conocimiento y formar parte de su transmisión.

Elizabeth Jelin (2002), por su parte, habla sobre "vehículos de la memoria", refiriéndose tanto a libros y archivos como a expresiones y actuaciones "que antes de representar el pasado, lo incorporan performativamente" (p. 37). Al hacerlo, se movilizan sentidos, se ubican hitos espaciales y temporales y se le da un significado, un propósito y un futuro al acto y al trabajo de la memoria. Son esfuerzos colectivos que establecen relaciones entre el pasado, el presente y el futuro, y entre los dolores de las víctimas, los hechos y sus responsables.

Si consideramos que estas formas expresivas y performativas transmiten la memoria por medio de una producción de significados que se originan en el cuerpo y los sentidos, y que contienen elementos argumentales y narrativas no reducibles al lenguaje, se propone un nuevo tipo de 
discurso denominado "repertorios simbólicos del testimonio". Esta categoría se constituye en una forma de canalizar las estrategias usadas por las organizaciones de víctimas en su necesidad de visibilizar el clamor colectivo en busca de reconciliación. Dado el momento histórico que vive Colombia de urgencia y de clamor colectivo, dos condiciones clásicas del testimonio, ${ }^{1}$ los repertorios simbólicos testimoniales se constituyen en una nueva definición que responde a los desafíos del siglo Xxı.

Esta idea surgió como una respuesta a la necesidad de nombrar las iniciativas de memoria surgidas en los últimos años en Colombia, que no se acogen a prácticas narrativas estructuradas ni se ubican con claridad dentro de un lenguaje que las designe uniformemente.

El informe del Grupo de Memoria Histórica define estas iniciativas como "procesos permanentes, impulsados por movimientos de víctimas como prácticas puntuales de resistencia que implican formas de subjetividad colectiva y que buscan restaurar la dignidad y la cotidianidad laceradas por la violencia" (CNRR, 2009, p. 18). El informe destaca el carácter "fundacional" de la memoria refiriéndose a "iniciativas" antes que a "trabajos". Estas iniciativas tienen en común que miran hacia delante sin ignorar el pasado, afirman en el presente un futuro abierto que al mismo tiempo restauran y renuevan las formas de vida comunitaria (CNRR, 2009, p.18).

En un informe del Centro Internacional para la Justicia Transicional (ICJT por sus siglas en inglés) titulado "Recordar en conflicto: iniciativas no oficiales de la memoria" (Briceño-Donn, Reátegui, Rivera y Uprimny, 2009), Felix Reátegui afirma que la memoria es un factor constituyente del espacio público que comunica lo social con lo político. Para este autor, la memoria es una sustancia social que puede ser eficaz tanto para la consolidación de un poder como para desafiarlo, transformarlo o desestabilizarlo. Por lo tanto, "se convierte en un ingrediente importante de la malla simbólica en la que se sostienen nuestros ordenamientos sociales, ya sean oficiales o de individuos y colectividades" (2009, pp. 24-25). Un elemento que Reátegui considera paradójico es comprender cómo a partir de la violencia, la producción de la memoria nacional tradicionalmente generada por las élites ilustradas e intelectuales, se ha transformado a "una irrupción reciente de la memoria de las víctimas: de sus testimonios y de las formas propias, no académicas, no letradas, de rendir versiones del pasado en la esfera pública" (2009, p. 27).

Reáteguí señala que el proceso que se está dando en Colombia responde a los procesos de violencia que ha vivido el continente. Se trata de memorias heterogéneas y diversas: "memorias que no necesariamente privilegian la expresión verbal, sino que se sienten mejor expresadas en

1 La definición clásica de John Beverly estipulaba que el testimonio latinoamericano requería de dos elementos esenciales: urgencia y solidaridad (1989, p. 14). 
la acción y en el performance, memorias que reposan sobre supuestos diversos acerca de la relación con el poder y el Estado" (2009, p. 27).

Por su parte, María Victoria Uribe en su ensayo "Iniciativas no oficiales: un repertorio de memorias vivas" (2009), hace una recopilación de los repertorios que se han dado en Colombia a lo largo del territorio y que intentan preservar o transformar experiencias traumáticas relacionadas con el conflicto armado. Según Uribe, se trata de prácticas, representaciones y significados que construyen las comunidades y organizaciones afectadas por la violencia con el fin de hacer público su dolor y denunciar las injusticias de las que han sido objetos. Son prácticas de resistencia contra la impunidad y el olvido e inciden en la recuperación de la autoestima y la confianza (2009, p. 44).

Dentro de la categoría de los performances, Uribe sigue a Taylor en cuanto a la definición de la misma como "un tesoro de inventiva que permite la agencia individual" (2009, p. 58). Esta categoría incluye tejidos, pinturas y dibujo, fotografías, cartografías, mapas mentales, álbumes de memoria, iniciativas sonoras y canciones y programas radiales. También se refiere a las iniciativas textuales que incluyen los libros de memoria y archivos documentales.

En este sentido el testimonio femenino contemporáneo en un país como Colombia se ha transformado de acuerdo a las necesidades que han surgido en la región. Actualmente, es evidente que el testimonio debe incluir la memoria, el cuerpo y la sanación de los traumas causados por la violencia política. Veena Das (2008) señala que los testimonios femeninos deben entenderse desde la cotidianidad de las hablantes, estructurados por tradiciones simbólicas. Es por eso que las formas testimoniales no se pueden entender desde el análisis textual, sino que hay que comprenderlas en su sociabilidad (citada por Ortega, 2008, p. 40). Para Das, las expresiones testimoniales producto de memorias reprimidas propician zonas de silencio que se deben encauzar en otras manifestaciones. Muchas veces, esas zonas solo pueden aflorar dentro de experiencias sociales que privilegian la solidaridad. Por eso, según Das, el testimonio se debe abordar a través de complejas relaciones entre el cuerpo y el lenguaje porque en esa intersección se encuentran los recursos "para decir y mostrar el dolor y ofrecer testimonio al daño infligido en el tejido social" (citada por Ortega, 2008, p. 47).

En este ensayo se propone que las nuevas formas testimoniales femeninas plantean una relación cuerpo-memoria-performance. Es decir que el proceso testimonial se construye con prácticas que surgen desde el cuerpo para resignificar experiencias traumáticas en forma de expresión artística convirtiendo el dolor en agencia y la resistencia en acciones de solidaridad a nivel colectivo.

A continuación se analizan varios ejemplos de este tipo de prácticas denominados en esta investigación "repertorios simbólicos testimoniales", 
que han apropiado las mujeres de la Ruta Pacífica como formas de canalizar la memoria, reconstruir el tejido social y transmitir una pedagogía de paz con perspectiva de género a lo largo del país. Se analizan los testimonios en su forma clásica recogidos en los tomos La verdad de las mujeres: Víctimas del conflicto armado en Colombia (2013) y El camino de vuelta de la memoria (2015); repertorios artísticos como el mural de la Ruta, y las iniciativas pedagógicas a través de escuelas y talleres itinerantes regionales que adelanta actualmente la organización.

\section{La verdad de las mujeres (testimonios)}

En el año 2013 la Ruta Pacífica de las Mujeres dio a conocer dos tomos de testimonios con el título La verdad de las mujeres: víctimas del conflicto armado en Colombia. Este informe forma parte de un proyecto realizado por la Comisión de la Verdad y de la Memoria Histórica de las Mujeres creada por la Ruta Pacífica como una estrategia que aporta a la negociación del conflicto armado desde la paz y la reconciliación. Igualmente, representa un modelo para una eventual Comisión de la Verdad a nivel nacional que reúna a todos los actores y víctimas de la violencia.

El proyecto constituyó un esfuerzo colectivo de un equipo confirmado por investigadoras, codificadoras, sistematizadoras de datos, digitadoras y colaboradoras externas. El informe final es único como testimonio porque registra "una experiencia desde la base protagonizada por las mujeres víctimas y que pone sus voces en el centro del proceso de construcción de una verdad colectiva narrada por ellas como parte de la historia reciente de Colombia" (Ruta Pacífica de las Mujeres, 2013a, p. 11). La metodología seguida recogió 933 testimonios narrados en primera persona sobre las experiencias de violencia, experimentados en nueve grupos focales en zonas de conflicto a lo largo del país y once casos de colectivos de víctimas, para un total de mil testimonios.

La elaboración del informe pasó por un proceso de tres fases: diagnóstico, recolección de entrevistas, elaboración y divulgación. Cada paso tuvo en cuenta la formación del equipo investigador con talleres dirigidos a sensibilizar, entrenar y diseñar estrategias que permitieran el acercamiento hacia las mujeres víctimas con apoyo psicosocial. Posteriormente, las documentadoras recolectaron la información en cada regional con el acompañamiento de las coordinadoras de cada seccional. Finalmente, la información se sistematizó para la construcción del informe final en dos tomos y un resumen, otro volumen dedicado a explicar la metodología utilizada y a reflexionar sobre los elementos adicionales al proceso, titulado Memoria para la vida: una Comisión de la Verdad desde las mujeres para Colombia (2013b). Además, se produjo un video titulado Memoria, jardín

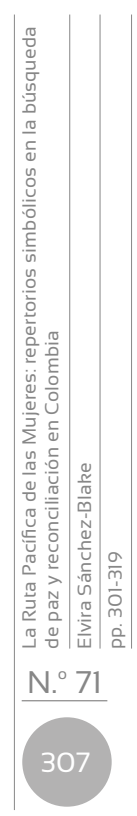


de la esperanza de las mujeres ${ }^{2}$ que se ha divulgado por diferentes medios, la academia, instituciones e internet. El informe final le mereció a la Ruta Pacífica el Premio Nacional de Paz 2014. El proyecto ha continuado con la publicación de un segundo volumen, titulado El camino de vuelta de la memoria (2015), y con la realización de talleres, movilizaciones, encuentros regionales para la paz y otras actividades a nivel local y regional.

Los testimonios presentados poseen características singulares que los distinguen de otros relatos testimoniales. Cada tomo incluye análisis, documentación estadística, contexto y categorías para comprender la dimensión de las historias. Las narraciones se presentan en forma anónima, de manera que las vivencias se convierten en una voz colectiva. Los testimonios como tales se incluyen en forma de viñetas que extraen las experiencias contadas en primera persona insertadas dentro del análisis como una forma de documentar y reflejar los efectos del conflicto armado en las mujeres colombianas.

Como investigación, el informe se centra en las experiencias de las víctimas y construye una memoria colectiva que reúne muchas características similares. Además de registrar los hechos, documenta cómo los vivieron las mujeres, las consecuencias que tuvieron, cómo los han afrontado, y cómo miran hacia el futuro como sobrevivientes. Otra particularidad es que el informe no victimiza ni recaba en los hechos traumáticos. Por el contrario, evade la estigmatización y se enfoca en el proceso de recomposición y reparación del tejido social. Las testimoniantes no solo hablan de sus sufrimientos sino de sus resistencias, de sus esperanzas y de sus concepciones de una paz duradera. En este sentido, la memoria se construye hacia una transformación de la sociedad.

Además, el proceso no se ha limitado a divulgar los resultados de la investigación, sino que continúa otorgando apoyo a las testimoniantes en los procesos de recomponer sus vidas con soporte psicosocial y de apoyo al acceso a los mecanismos legales de reparación y restitución. Por otro lado, muchas de las mujeres entrevistadas han continuado participando en las actividades de la Ruta Pacífica, y de ese vínculo han surgido nuevas agrupaciones, lazos de solidaridad, acceso a escuelas de formación y en muchos casos, las mujeres se han convertido en voceras y líderes de sus propias comunidades.

La verdad de las mujeres subraya la importancia de la memoria y de la verdad. Ambos términos convergen en la trascendencia de sacar a la luz hechos que habían sido silenciados por temor no solo a represalias, sino por la carga socio-afectiva que significa desentrañar episodios traumáticos como abusos sexuales, atropellos contra la dignidad, señalamiento por parte de la sociedad y del discurso dominante. En muchos 
casos, ser desplazado o desplazada provoca conexiones de simpatía o afiliación a grupos armados. Ser objetos de violaciones o vejaciones sexuales connota comportamientos provocadores. Ser víctima del conflicto es en sí un distintivo de deshonra e indignidad en la sociedad colombiana. Por eso, al proveer un espacio donde las mujeres construyen desde sus subjetividades una verdad de memoria colectiva que legitima experiencias compartidas similares se recupera la confianza, la dignidad y la esperanza. Así, según el informe:

Establecer la memoria de la verdad desde las mujeres es una ganancia de libertad porque ellas se han hecho dueñas de la propia memoria para que ésta no se instrumentalice. Quiere decir que las mujeres han dado significado, sentido propio, a esta experiencia sustrayéndose al orden de interpretación de los hechos establecidos por el patriarcado que confirma una y otra vez la victimización de las mujeres incluso cuando pretende denunciar la violencia contra ellas (Ruta Pacífica de las Mujeres, 2013a, p. 23).

La memoria de la verdad crea una nueva dimensión del discurso histórico. Al sacar a la luz los testimonios de una gran mayoría de mujeres víctimas de la violencia en el territorio colombiano, principalmente en zonas aisladas y marginadas, se cuestiona la verdad de un discurso dominante parcializado y excluyente. "Con esta verdad se abre por una parte la posibilidad de que las experiencias de la diferencia sean nombradas y escuchadas, y por otra parte, se enriquecen los significados de la experiencia humana que va conformando el discurso histórico" (Ruta Pacífica de las Mujeres, 2013a, p. 23).

En las conclusiones y recomendaciones del informe se destaca la importancia de tener en cuenta la voz de las víctimas en los procesos de paz y la necesidad de reconocer y constatar los efectos del conflicto armado en el cuerpo y la vida de las mujeres. La afirmación de que el conflicto armado pasa por el cuerpo de las mujeres es una constante a lo largo de los testimonios. El documento evidencia que las mayores vejaciones se ejercen sobre la sexualidad y la integridad física de las mujeres como castigo a su dignidad. Se subraya además la normalización y la invisibilización de las violencias como un factor clave en mantener el continuum de estas violencias. Dentro de esas categorías se destacan la violencia física, psicológica y sexual (Ruta Pacífica de las Mujeres, 2013a, p. 44), pero se registran otras formas indirectas como la ley del silencio ejercida por el terror, la intimidación, el control de los cuerpos y de los comportamientos, el despojo, como formas de violencias ejercidas por los actores armados que afectan tanto el cuerpo individual como el tejido social.

Como testimonio el informe señala que la posibilidad de hablar y compartir experiencias y memorias traumáticas sirve como catalizador del

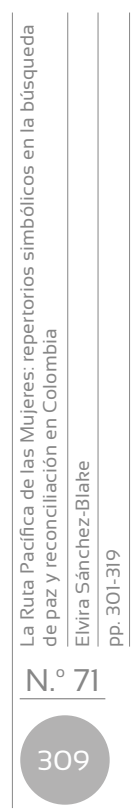


quebranto operado en el ser de las mujeres afectadas. Además, al construir una memoria compartida les posibilita ámbitos de acción para "resistir, movilizarse y rehacer las condiciones de humanidad" (Ruta Pacífica de las Mujeres, 2013a, p. 61). Un elemento esencial del informe es su neutralidad. Se pone de relieve que la mayoría de las mujeres entrevistadas evitan identificar a los perpetradores. Se infiere que puede ser por temor a represalias, pero en muchos casos es simplemente porque todos los victimarios configuran una amenaza por igual. Tanto la guerrilla como los paramilitares, el Ejército y la Policía son ante los ojos de muchas víctimas, actores que ejercen los mismos tipos de abusos de poder y de agresiones. Es por eso que dentro de las recomendaciones del informe se incluye desmovilizar y desarmar a los diferentes grupos armados, tanto subversivos o ilegales, como a los estatales y a las Ilamadas fuerzas del orden. La premisa de que todos los actores armados ejercen la violencia está presentes en todos los testimonios. Así lo resume la coordinadora de la Ruta Pacífica, seccional Valle del Cauca, María Teresa Arizabaleta, quien asegura que donde hay un hombre armado hay violencia: "Aparece un uniformado en una esquina y en la otra hay un hombre golpeando a la mujer" (entrevista) ${ }^{3}$. Por lo tanto, la recomendación del informe reza así:

La desmilitarización debe darse en el desmonte programado de la hipertrofia que ha traído el militarismo en las fuerzas armadas y de seguridad privadas y los mecanismos de observación en los que puedan participar las mujeres con condiciones de seguridad" (Ruta Pacífica de las Mujeres, 2013a, p. 101).

\section{La devolución}

Un segundo paso del proyecto de la Comisión de la Verdad y Memoria de Mujeres Colombianas fue la publicación de un tomo que recoge las reflexiones y experiencias vividas durante la recolección y el procesamiento de los testimonios, titulado El camino de vuelta de la memoria (2015). En este libro se documenta el proceso que denominan "devolución", es decir las actividades realizadas para dar a conocer el informe en cada región. Fue así como se realizaron talleres con los grupos focales que habían participado en los testimonios y se llevaron a cabo actividades que incluían la explicación del informe, y una mesa de diálogo con las participantes para conocer sus percepciones y el impacto de su experiencia tanto para ellas como para el público en general. Es importante resaltar que los informes de memoria terminan con la publicación y divulgación de la información recogida. En este caso, la Ruta Pacífica comprendió

3 Entrevista para el programa Mujeres rompiendo el silencio. Canal 2 de Televisión, Valle del Cauca. Junio, 2015. 
que los procesos de memoria deben devolver el sentido primordial del testimonio a los individuos y a las comunidades que aportaron al trabajo de reconocimiento de la verdad.

En este sentido, el proyecto como totalidad refleja la concepción del testimonio señalada por Veena Das (2003), quien destaca la importancia de incluir la memoria, el cuerpo y la sanación de los traumas causados por la violencia política. Según Das, "nombrar la violencia no refleja únicamente luchas semánticas, refleja el punto en el que el cuerpo del lenguaje resulta indiferenciable del cuerpo del mundo y el acto de nombrar constituye una expresión performativa" (2003, p. 146). De esta forma, la sanación no es solamente recabar en la memoria de los hechos, sino en la resignificación de las acciones que conllevan una transformación hacia el futuro y conducen a la construcción de redes de solidaridad. Esta nueva forma de testimoniar comprende también que las lecciones aprendidas se dan en doble vía, tanto en las investigadoras como en las entrevistadas el proceso de aprendizaje constituyó un intercambio mutuo de saberes y poderes. Por último, el proceso de devolución rescató otro de los elementos señalados por Das, el de apropiar y utilizar los repertorios simbólicos que tienen especial significado dentro de los entornos culturales, tradicionales y rituales de cada región.

\section{Talleres de memoria simbólica}

Como parte de los encuentros regionales realizados en las nueve regiones donde se recogieron los testimonios, se llevaron a cabo talleres de devolución. Los talleres se concibieron como lugares de encuentro, con un tiempo destinado a reflexionar con espacios creativos de distensión, sanación y autocuidado. Además, a cada participante se le entregó un cuaderno de experiencia para que consignara sus reflexiones y aprendizajes en forma individual.

Este proceso se realizó en torno a repertorios simbólicos y lenguajes expresivos. El primero de ellos fue el del tejido. Las participantes, en este caso las víctimas de la violencia, que dieron su testimonio se denominaron las "Tejedoras de la Verdad" y las encargadas de tomar sus testimonios se llamaron "las Hilanderas", para significar así los hilos que aportan la memoria y las que las tejen como un proceso conjunto. Las responsables regionales fueron las "Moiras de la Caracola", por representar el eje en torno al cual se tejió la memoria y se hizo posible el proyecto colectivo. Por último, "las Amistavientos", las amistades que trae el viento, fue el nombre otorgado al equipo de devolución que participó en los talleres (El camino de vuelta, 2015, p. 24).

Es importante resaltar el carácter simbólico que tuvo cada uno de estos talleres. Como participante del encuentro que tuvo lugar en la Casa

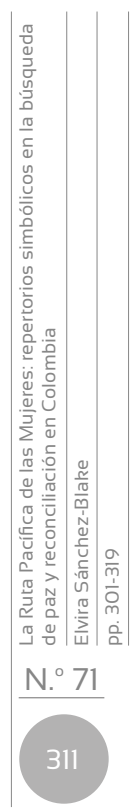


Matria de Cali el 5 de junio del $2015^{4}$, me permito relatar la experiencia destacando el uso y manejo de las expresiones simbólicas. Desde el momento de Ilegada, el espacio está preparado con música ambiental. A cada mujer se le entrega una mariposa con su nombre, y se le ofrece un aceite relajante de lavanda para que se frote las manos con él. Las mujeres inician la subida hacia el sitio de la reunión por unas escalas con huellas pintadas que significan el recorrido de vuelta a la memoria. Al ingresar al sitio de la reunión se encuentran con una tela pintada que representa la portada del libro El camino de vuelta, que consiste en una mujer rodeada de mariposas, flores, aves, huellas y caracolas; así se representa el ingreso a las páginas del libro. En el espacio de la reunión se hallan varios elementos simbólicos: una mándala, símbolo de congregación, y las imágenes de las diosas de la verdad y la memoria, elementos constitutivos del proceso reparador. En otros rincones se encuentran velas, cintas, tejidos, almendras, mariposas y las herramientas que se utilizan durante el encuentro. El taller se inicia con la presentación del video Memoria, jardín de la esperanza de las mujeres. Como este video relata y contiene la experiencia de trabajo de la Comisión de la Verdad, muchas de las asistentes se relacionan con su contenido e incluso participaron como entrevistadas. A continuación se presenta el informe testimonial y se hace una reflexión sobre lo que significó narrar sus experiencias y el impacto que ha tenido en cada una de ellas. En esta oportunidad algunas de las mujeres recalcaron la necesidad de seguir divulgando las consecuencias del conflicto y reclamando responsabilidades.

Posteriormente se lleva a cabo una actividad Ilamada el tejido de la memoria. Las participantes se organizan en un círculo y cada cual lanza un ovillo de lana a otra mientras expresa en voz alta lo que para ella representa "la memoria". A medida que el ovillo viaja de un lado a otro se va construyendo una red que entrelaza a las participantes. Este repertorio representa una forma de reconstrucción de la memoria desde el tejido individual y comunal con una expresión cargada de solidaridad. Además, el ejercicio en sí propició una zona de distensión y comodidad entre las participantes. Al final se consolidó una complicidad entre ellas. Más tarde, se realizó otra actividad enfocada a comprender los tipos de violencias que se "normalizan" en la sociedad. Las asistentes se dividieron en parejas con el propósito de entrevistarse mutuamente sobre las formas de violencia que han experimentado en su vida, incluyendo las personales, domésticas, sociales y políticas. Esta actividad tuvo como objetivo reflexionar sobre las formas de violencia que son parte de la vida cotidiana y de las que en muchos casos no existe conciencia. El resultado de este ejercicio fue la creación del árbol de violencias, un repertorio simbólico

4 Este taller formó parte de un proyecto a nivel municipal para formación de líderes de paz en el Valle del Cauca. 
que representó las múltiples y variadas formas de violencia que subsisten en la sociedad y que deben ser concientizadas, denunciadas y confrontadas. El proceso de devolución recogido en El camino de vuelta de la memoria, así como las actividades realizadas con las regionales ha sido visualizado y expresado en diversas formas pictóricas y artísticas.

\section{El mural de la Ruta}

Uno de los repertorios testimoniales que ha encontrado una gran acogida en el medio de las colectividades de mujeres es el de las artes plásticas. El acto de plasmar en un cuadro, una pintura o un mural las experiencias de trauma y de dolor rescata la memoria y convierte el recuerdo en esa representación tangible que revive y restituye el trauma que se quiere superar. Los repertorios de este tipo, en palabras de Taylor, funcionan como actos vitales de transferencia que transmiten un saber social, de memoria y sentido de identidad a través de prácticas culturales y estéticas (2003).

Como parte de las iniciativas de seguimiento al proyecto de la Comisión de la Verdad, la regional del Valle del Cauca puso en marcha el diseño y elaboración del Mural de la Ruta en la ciudad de Cali. Este mural se creó con el propósito de rescatar la memoria colectiva de las mujeres víctimas del desplazamiento de la zona suroccidente del país que habían participado como testimoniantes en el informe de la Comisión. El proceso del mural incluyó un taller de aprendizaje de técnicas artísticas, selección de imágenes, actividades comunales, limpieza y adecuación de la zona, el acto de pintura y celebración del mural concluido. En calidad de participante y observadora del proceso, tuve la oportunidad de constatar que las actividades que precedieron la pintura del mural fueron más significativas que el resultado final. En los talleres, el artista Eric Fernández y la psicóloga Tatiana Osorio les enseñaron a las participantes a dibujar desde sus propias experiencias. Las mujeres, un poco temerosas al principio, luego con más confianza, plasmaron en dibujos sencillos lo que representó para ellas la salida de sus lugares de origen como víctimas de desplazamiento. Algunas diseñaban una imagen, otras, una serie de cuadros sucesivos, otras representaban los objetos que dejaron atrás o su casa con sus animales y vegetación circundante. En medio de estos talleres se generaban lazos de solidaridad y de reflexión sobre las experiencias compartidas. La memoria positiva o ejemplar de la que habla Todorov $(2000)^{5}$, se hacía evidente cuando algunas de las participantes comentaban "ahora puedo contar

5 Todorov señala que los acontecimientos recuperados por la memoria pueden ser leídos de manera literal o de manera ejemplar. La primera extiende el trauma a todos los instantes de la existencia y establece una continuidad de odios, mientras el segundo, construye un ejemplo, y de él se extrae una lección. El pasado se convierte en principio de acción para el presente (2000).

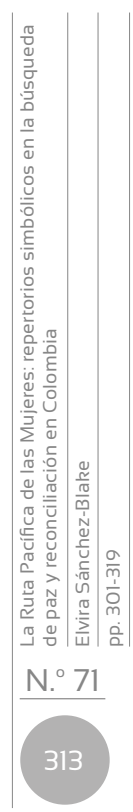


mi experiencia porque no soy la única". Efectivamente, el estigma de ser desplazadas deja de serlo cuando son varias las que comparten la misma circunstancia y pueden transmitirlo sin recabar en la victimización, sino en el empoderamiento que produce exteriorizar una experiencia colectiva. La pintura seleccionada para ser el centro del mural fue el de una figura de mujer que sale de su pueblo cargando un bebé en la espalda. La figura frontal se destaca en la pintura por la fuerza de su rostro y la determinación de su mirada. En el centro del pecho se aprecia una casa, que significa que lleva su casa en el corazón. El día de la pintura del mural las participantes plasmaron en el mural sus diseños alrededor de la figura central ${ }^{6}$.

Durante los días previos a la ejecución del mural se celebraron mingas, una olla comunal donde todas participan en la cocción y la comida; exposición artesanal de los productos que tejen y elaboran muchas de las integrantes del colectivo, y cantos y representaciones de artistas invitados. Alrededor de estas actividades sobresalía la energía que produce la solidaridad: la resignificación de saberes y poderes, el crecimiento como individuos y la fuerza de colectividad. Al entrevistar a Ignacia Roca, la mujer cuya pintura fue seleccionada como centro del mural, ella reconoció el apoyo que ha recibido de la Ruta para superar su dolor y las herramientas que ha encontrado para convertirse en líder de su propia familia y comunidad. El hecho de plasmar su propia experiencia en una pintura significa exteriorizar su dolor en forma simbólica al tiempo que su condición de desplazada deja de ser un estigma para convertirse en un instrumento de restitución ${ }^{7}$. De esta forma, el repertorio artístico como testimonio adquiere una nueva semantización en su función de memoria corporal que transmite conocimiento, reconocimiento y dignidad.

\section{Pedagogía de paz}

La Ruta Pacífica continúa el proceso de reafirmar el accionar y el quehacer de las mujeres en las regiones a través de movilizaciones, encuentros regionales, cumbres por la paz y escuelas de incidencia política. Varias de estas iniciativas provienen de proyectos conjuntos de instituciones públicas y privadas que las invitan a colaborar con su experiencia y enfoque vivencial. El propósito es avanzar en la capacitación de las mujeres que han sufrido los impactos de la violencia hacia nuevos espacios de acción. La escuela de incidencia política en Cali que tuvo lugar durante el segundo semestre del 2015 es un ejemplo. El objetivo de la escuela se formula de esta manera:

6 Ver el video sobre el mural en https://www.youtube.com/watch?v=H1USuh4GKdU

7 La entrevista con Ignacia Roca tuvo lugar el 15 de abril de 2015 en Cali, Valle del Cauca. 
Propiciar una formación integral social y holística centrada en el empoderamiento, el ejercicio de liderazgo y el aprehender conocimientos, conceptos y metodologías para la participación y la incidencia efectiva desde el reconocimiento del ser, y el hacer, que les permita situarse en un horizonte coherente con la realidad social y de esta manera, contribuir competente y éticamente en la solución de problemas que emergen del contexto en relación con la persona, la familia, las organizaciones y la sociedad en general. (Ruta Pacífica de las Mujeres, 2016)

Siguiendo los mismos postulados, la Ruta llevó a cabo en el primer semestre del 2016 la escuela itinerante de Palmira "Trenzando Saberes y Poderes". Entre sus objetivos se destaca el desarrollo de las capacidades de las mujeres para el ejercicio ciudadano individual y colectivo a partir del reconocimiento y la valoración de su experiencia comunitaria, su creatividad, su saber ancestral. Igualmente, se intenta fortalecer las potencialidades para la incidencia colaborativa y la implementación de la Política Pública para la Equidad de Género. A partir de varios módulos que se desarrollan por jornadas de dos semanas en un periodo de cuatro meses, las mujeres adquieren destrezas de comunicación, planificación, organización y alianzas necesarias para ejercer el liderazgo político. Asimismo, aprenden a manejar los instrumentos de práctica de políticas de género, construcción de mapas de poder territorial, planes de acción de política pública y liderazgo con enfoque de género (Ruta Pacífica de las Mujeres, 2016). Aparte de los módulos de aprendizaje, se realizaron agendas en los territorios, es decir, en las comunidades rurales adscritas al municipio, identificando las necesidades de cada zona y construyendo agendas para cada localidad.

\section{Aprender desaprendiendo}

El propósito de estas escuelas de incidencia política es avanzar en la formación de las mujeres que han sufrido los impactos de la violencia hacia nuevos espacios de acción. Se trata de superar la victimización y el asistencialismo para entrar en la etapa de agencia y liderazgo y avanzar en la aplicación de la agenda política propuesta por la Ruta Pacífica para la transición hacia la paz en Colombia. Estos tipos de iniciativas aplican uno de las consignas fundamentales de la Ruta: "aprender-desaprendiendo", transformando el entorno y cambiando las estructuras de dominación simbólicas que desmontan los condicionamientos de género y de desigualdad social $^{8}$. Como instrumentos esenciales se utilizan los repertorios simbólicos tales como los talleres de memoria, prácticas del reconocimiento del

8 Entrevista con Elizabeth Ortega, líder de la seccional Ruta Pacífica Palmira. Marzo 10, 2015. Cali, Colombia. 
cuerpo y de sus potencialidades, así como las danzas, los performances, las puestas en escena, todas esas experiencias vivenciales como fundamento del enfoque pedagógico orientado hacia la paz.

Las iniciativas mencionadas están acompañados de las acciones que desarrolla la Ruta, como marchas, movilizaciones, "batucadas", encuentros, asambleas, cumbres regionales, con el fin de visibilizar su trabajo y avanzar en su agenda de paz. Todos estos proyectos tienen como objetivo a largo plazo crear nuevas ciudadanas que posean las herramientas para colaborar, aportar y cambiar la normatividad que rige la sociedad. En este proceso, el trabajo de la Ruta no solo está formando nuevas ciudadanas y potenciando sus capacidades, sino concientizando a los estamentos públicos y privados en cuanto al valor y los derechos fundamentales de las mujeres. Esto se hace evidente en los cambios de percepción de los roles genéricos y la transformación de las percepciones a nivel social, político, económico y a nivel privado en el aspecto doméstico y familiar. En el escenario legal, los reconocimientos de las mujeres en leyes que denuncian los abusos sexuales y los feminicidios forman parte de esa concientización. Aun en el plano semántico, las transformaciones en el uso del lenguaje que incorpora el género femenino en nuevas acepciones y terminología visibilizan el cambio de mentalidad. Finalmente, estas iniciativas en conjunto con otras prácticas y proyectos por parte de diversas organizaciones están incidiendo en crear las condiciones para un nuevo país, donde se tengan en cuenta los derechos de todos sus integrantes respetando la diferencia y la dignidad de las mujeres.

\section{Conclusión}

Si tenemos en cuenta que, como señala Rosana Rodríguez (2013), el testimonio femenino parte de un territorio que es anterior a la palabra, que nace de la experiencia corporal y de experiencias hondamente traumáticas difíciles de nombrar, las iniciativas adelantadas por la Ruta Pacífica de las Mujeres en Colombia constituyen una nueva forma de accionar que incluye los repertorios simbólicos testimoniales con un propósito de transformación a nivel de subjetividades de género, de individuo y de sociedad.

Los repertorios analizados en este artículo demuestran que el testimonio femenino contemporáneo se sitúa en zonas que no ingresan solo en el orden del discurso. Son experiencias que, en palabras de Rodríguez, "tardan en adquirir nominación [...] que quedan en el reborde de lo

9 Las batucadas forman parte de las movilizaciones y consisten en grupos de mujeres que tocan tambores o "batucas" fuertemente a la vez que se gritan consignas. El propósito es llamar la atención alrededor de círculos de activistas que generan energía y reconocimiento. 
enunciado y que no pueden ser plenamente admitidas" (2013, p. 1161). En las iniciativas mencionadas se destaca la importancia del cuerpo, la memoria y la sanación. Así lo ha entendido la Ruta Pacífica en sus veinte años de accionar como colectivo. Por eso la premisa "el conflicto atraviesa el cuerpo de las mujeres" revierte su connotación de victimización para convertirse en vehículos de agencia y empoderamiento. Puesto que los cuerpos de las mujeres han sido y son territorios de combates, de experiencias hondamente traumáticas difíciles de nombrar, es ahí donde el testimonio encuentra su cauce en los repertorios pre-discursivos, en las prácticas orales, gestuales, culturales y rituales que se elaboran en colectividad. Los repertorios descritos, tales como los talleres de memoria, las expresiones simbólicas, y las escuelas de incidencia analizados, se constituyen en formas privilegiadas de testimoniar las experiencias traumáticas del conflicto que ha vivido Colombia en expresiones que reafirman una nueva forma de poder y de agencia individual y colectiva. 


\section{Referencias bibliográficas}

Beverly, J. (1989). The margin at the center. Modern Fiction Studies, 35 (1), 11-29.

Briceño-Donn, M.; Reátegui, F.; Rivera, M. C. y Uprimny Salazar, C. (eds.). (2009). Recordar en conflicto: iniciativas no oficiales de memoria en Colombia. Bogotá: Centro Internacional para la Justicia Transicional.

Comisión Nacional de Reparación y Reconciliación. . Grupo de Memoria Histórica (2009). Memorias en tiempos de guerra. Repertorio de iniciativas. Bogotá: Puntoaparte.

Das, V. (2003). Trauma \& Testimony: Implications for Political Community. Anthropological Theory, 3, 293-307.

Mujeres en Zona de Conflicto y Corporación Sisma Mujer. (2010). Mujeres en zona de conflicto: Diagnóstico Mujer, Paz y Seguridad.Los movimientos de mujeres, y paz en Colombia. Desde los años noventa hasta hoy.

Jelin, E. (2002). Los trabajos de la memoria. España: Siglo Veintiuno.

Ortega, F. (ed.). (2008). Veena Das: Sujetos del dolor, agentes de dignidad. Bogotá y Medellín: Universidad Javeriana, Instituto Pensar, Universidad Nacional de Colombia y Facultad de Ciencias Humanas - Instituto CES.

Reátegui Carrillo, F. (2009). Las víctimas recuerdan: Notas sobre la práctica social de la memoria. En M. Briceño-Donn, F. Reátegui, M. C. Rivera y C. Uprimny Salazar (eds.). Recordar en conflicto: iniciativas no oficiales de memoria en Colombia (pp. 17-43). Bogotá: Centro Internacional para la Justicia Transicional.

Rodríguez, R. (2013). El poder del testimonio: experiencias de mujeres. Revista de Estudios Feministas, 21 (3) 1149-1169.

Ruta Pacífica de las Mujeres. (2013a). La verdad de las mujeres: víctimas del conflicto armado en Colombia (resumen). Bogotá: G2 Editores.

Ruta Pacífica de las Mujeres. (2013b). Memoria para la vida: una Comisión de la Verdad desde las mujeres para Colombia. Bilbao: Universidad del País Vasco.

Ruta Pacífica de las Mujeres. (2015). El camino de vuelta de la memoria. Bogotá: Ruta Pacífica, coordinación general.

Ruta Pacífica de las Mujeres. (2016). Proyecto Escuela Visibilizante. Política pública de equidad de género mujeres Palmira: "Trenzando saberes y poderes" [folleto informativo].

Taylor, D. (2003). The archive and the repertoire: Performing cultural memory in the Americas. Durham/London: Duke University Press.

Todorov, T. (2000). Los abusos de la memoria. (M. Salazar, trad.). Barcelona: Paidós, Ibérica. 
Uribe, M. V. (2009). Iniciativas no oficiales: un repertorio de memorias vivas. En M. Briceño-Donn, F. Reátegui, M. C. Rivera y C. Uprimny Salazar (eds.). Recordar en conflicto: iniciativas no oficiales de memoria en Colombia (pp. 43-72). Bogotá: Centro Internacional para la Justicia Transicional. 